\title{
Research on the Negative Implications of Shadow Education for Primary School Students
}

\author{
Xin Gao* \\ Faculty of Educational Sciences, Jilin Engineering Normal University, Changchun 130000, China \\ *Corresponding author: Xin Gao, 865157438@qq.com
}

\begin{abstract}
In today's era, shadow education is becoming an important form of education in the education system. The pursuit of shadow education among parents and the dependence of students on it heightens its value. However, with the continuous development of shadow education, its profit-seeking nature has begun to appear, and many educational problems are surfacing in the development process. This paper studies shadow education on the basis of Marx's educational theories, such as the theory of all-round development and game theory. It analyzes the implications of shadow education which are not conducive to social or personal development, in order to continuously improve shadow education, provide better assistance for mainstream school education, and promote the comprehensive development of primary school students.
\end{abstract}

Keywords: Shadow education; Negative implications; Primary school students

Publication date: December 2021; Online publication: December 27, 2021

\section{Introduction}

As an important stage of a person's growth, primary schools lay the foundation for future development. This foundation is not only reflected in the level of knowledge, but also in the development of personality; hence, disregarding primary school education is unacceptable. With the younger age of social competition, primary school students have become the target of competition. In order to ensure that their children do not lose at the starting line, parents tend to blindly sign up their children for shadow education without considering their real needs, emotions, and the quality of these institutions. Shadow education, as the shadow of school education, originally came about as a supplement to school education, but it evolved into a copy of school education. It is a form of education that takes the school curriculum as the teaching content and aims to cultivate excellence or make up for certain differences. It exists outside the mainstream school education and charges a certain fee to help students acquire basic skills of specific subjects. With the rapid development of national economy and the improvement of living standards, the requirements for quality education among parents are also constantly increasing. The pursuit of cultural capital and the evaluation system of emphasizing the selection and screening of schools drive parents to invest heavily in their children's education, in order to obtain corresponding returns. Managers value this opportunity and throw themselves into the wave of shadow education. In recent years, shadow education has developed rapidly and magnificently in China.

According to Piaget's theory of the stages of cognitive development, primary school students are in the transition period from a concrete operational stage to a formal operational stage. During this period, the child's psychological and intellectual levels gradually mature, growing strong curiosity, energy, as well as lively and active characteristics. To some extent, the purpose of education is to "discipline" students, but it is not appropriate to be extravagant or apathic about it. Shadow education overcorrects this "discipline" of primary school students, putting an end to their fun and laughter as well as training primary school students 
to be "young but experienced." However, this is the failure of shadow education. Bing Xin, a writer, once said, "Let children grow like wild flowers." This should be the general guideline of modern education reform ${ }^{[1]}$. In Xunzi's Encouraging Learning, it is stated that the children of Han and Yue as well as those of the tribes of $\mathrm{Yi}$ and Mo are all born making the same sounds, but they grow up having different customs because the process of education has effected such changes in them. This illustrates the important role of education in an individual's physical and mental growth. Liu Qingchang, a scholar from Shanxi University, believes that education is a well-meaning intervention. In the Critique of Practical Reason, Kant mentioned that in the whole creation, man is the most intelligent and rational creature; his abilities and all his activities must be people-oriented, which should become the end of human activity itself ${ }^{[2]}$. All of these reveal the importance of education, in which education should be based on "people." Educatees should be assumed as the starting point and the end-result of any educational work, which lies in the concept of "all for students, and for all students." Therefore, in order to play a positive role in promoting shadow education to primary school students, it is necessary to follow the laws of physical and mental development of primary school students, determine the nearest development area of primary school students, correctly handle the relationship between external and internal causes, and fully stimulate students' subjective initiative. Only in this way can shadow education produce positive results. However, the vigorous development of shadow education has gradually revealed problems that hinder the growth of students and social development.

\section{The utilitarian goal of shadow education is not conducive to the development of students' spiritual attributes}

Shadow education, as the product of economic market development, is commercialized. As it is one of the forms of education, it plays a role in cultivating talents with education. Since everything is for the students, the starting point of shadow education should focus on the needs, skills, and emotions of primary school students. It should be based on the students, giving full play to the subjectivity of primary school students and weighing more on being educational than commercial, so as to promote a healthy and happy growth in addition to cultivate correct outlooks and life skills among primary school students. This is the natural state of shadow education. However, is it really that way?

With the gradual development of shadow education, the managers of these institutions assume profit as the school-running goal; in addition, the commercial attribute exceeds the educational attribute, which makes shadow education deviate from the essence of education and weaken education itself, strengthening the sociality and marketability. The utilitarianism of the school-running goal of shadow education benefits institutional managers in winning the attention of parents with various gimmicks in order to encourage parents to send their children to these institutions. In the minds of these managers, primary school students do not appear as "people," but rather, profitable tools, containers for knowledge storage, and robots that can work day and night ${ }^{[3]}$.

The first is the metaphor of students as tools for profit. Parents send their children to shadow education institutions for the purpose of improving their academic performance, giving full play to their advantages, and making up for their weaknesses. It is a common phenomenon where parents determine the quality of shadow educational institutions by their speed in raising the students' scores. Whichever organization produces good effect in raising scores, they would send their children to that organization. Shadow education focuses on this demand. In order to improve income, institutions usually use mechanical teaching forms to instill knowledge into the minds of primary school students in order to promote the improvement of their scores. Most parents only consider the superficial achievements of their children but neglect their real needs and subjectivity.

The second is the metaphor of primary school students as knowledge storage containers. In order to cater to the needs of the parents, shadow education pursues the improvement of students' academic 
achievements; thus, in the teaching process, cramming teaching methods are usually being used as elementary school students are looked upon as knowledge storage containers. Regardless of the students' independent thinking ability, teachers dominate the platform and force information into the students' heads; the teachers' absolute authority compels students to blindly follow them. "Do not resist, do not reflect, do not doubt, and just follow the teacher" - going on like this, primary school students would eventually become thoughtless creatures.

Finally, the metaphor of primary school students as robots that can work around the clock. The portrayal of robots is mainly reflected in two aspects: first, in recent years, with the younger age of competition, there is no lack of media exposure and the learning burden of primary school students is more due to running in schools and shadow education for a long time; with that, many "white-haired teenagers" have appeared; second, in shadow education institutions, these institutions improve the academic performance of primary school students by giving them numerous assignments; when education manipulates students like machines, and there is consistent response from them, the differences between the students are disregarded.

As an important stage of human growth, primary schools should pay attention to the cultivation of students' independent thinking ability, innovation, and creation. However, due to the biased school-running goals of managers, they do not consider the real needs of the students. Managers regard shadow institutions as factories, teachers as workers, and students as processed products, thereby unifying primary school students as one without any differences. Shadow education strengthens the students' knowledge attributes but does not cultivate their spiritual attributes.

\section{The single curriculum structure of shadow education is not conducive to the development of primary school students' social attributes}

Shadow education, as the shadow of mainstream school education, imitates school education step by step, neglecting the cultivation of primary school students' interpersonal communication and problem-solving skills. It one-sidedly caters to parents' preferences, assumes the achievement of better scores as the purpose of education, increases the academic burden of primary school students, and believes that it would eventually lead to the overall development of primary school students. There are two deficiencies in the curriculum structure of shadow education.

First, the type of shadow education courses is single. Shadow education mainly offers subject courses, with few comprehensive courses; subject courses occupy an absolute dominant position, while comprehensive courses hardly exist. The national curriculum has attracted much attention, while the local curriculum and school-based curriculum have not received substantial research. The renowned "test what, teach what" is emphasized. The single curriculum makes education play the value of one or several curriculum types, while neglecting the value of other curriculum types in the physical and mental development of primary school students, resulting in a one-sided development.

Second, the proportion of shadow education subjects is imbalance. There is an imbalance in the proportion of subjects in shadow education courses, with major subjects, such as Chinese, mathematics, and foreign languages, taking up a large proportion, whereas courses that improve students' communication and problem-solving skills are rarely offered in the subject setting of shadow education institutions due to a low market demand, thus depriving other subjects from promoting the development of primary school students. This directly affects the harmonious, comprehensive, and sustainable development of children's physical and mental health.

The basic idea of the eighth round of national curriculum reform in China is to focus on cultivating and developing students' innovative consciousness and skills in collecting and processing information as well as in acquiring new knowledge actively and independently. Shadow education emphasizes too much on 
subject-based education, focusing on mastering basic knowledge, while neglecting the improvement of basic skills and the shaping of students' ability and emotions. As time passes, primary school students would lack skills in communication and in dealing with things. This is not conducive to their overall development.

\section{Shadow education increases students' learning burden and is not conducive to the development of their natural attributes}

The Ministry of Education and other nine departments jointly issued the Measures to Reduce the Burden of Primary and Secondary School Students. Once it was released, school-running behaviors were standardized. However, this measure has become a crisis in the eyes of some parents; lest their children falling behind others and losing at the starting line, they tend to adopt high-pressure policies and enroll their children in some forms of shadow education. After receiving formal school education, primary school students still have to invest a lot of energy in shadow education. As a result, these students have no free time, have high possibility of myopia and neurasthenia, as well as grow a close resemblance to bean sprouts. The primary school age ranges from about 6 or 7 to 12 or 13. Based on Piaget's theory of stages of cognitive development, these children are in the transition from the concrete operational stage to the formal operational stage, in which the intellectual development of children is sequential. Educators are required to teach in accordance with the law of students' physical and mental development, step by step, and avoid "pulling up seedlings to encourage" and "to teach beyond the capacity of the learner." Therefore, shadow education should consider the physical and mental laws of children at this stage in regard to their teaching contents. Difficult knowledge contents that are obviously higher than the cognitive development level of primary school students or those that are too simple to the extent that they do not promote the cognitive development level should be omitted. By observing shadow education from this perspective, it can be appreciated that shadow institutions, on the one hand, tend to "jump the gun," which means that students are taught in advance in regard to knowledge contents. This is known as systems awareness. In theory, the early perception of knowledge can promote students to better digest and absorb new knowledge, but for primary school students who are easily distracted in the process of physical and mental development, they tend to lose their curiosity when being taught in class due to having a sense of familiarity with the teaching contents learned in advance, thus resulting in problems, such as dozing off and daydreaming; subsequently, this would reduce the learning efficiency. On the other hand, the teaching contents of some institutions are simple repetitions of what the students have already learned; this is known as review consolidation. Indeed, the act of reviewing to a certain extent can promote the firm grasp of the teaching content, but it is in the case of integrating and summarizing knowledge. Some institutions repeat the learned knowledge according to new curriculums, which would not achieve the purpose of induction and sorting, thus wasting students' time and effort.

People's Daily Online published an article about a father in Wuhan describing his experience of educating his children. He mentioned that since the third grade of primary school, his son has been forced by his mother to "cultivate excellence" in various shadow education institutions. There has never been a break for him. Over the past few years, his son has attended more than 30 classes, where he often starts at six in the morning and finally only resting at eleven at night. Even dinner is simply fixed on the way to the next course, from one to another. His son once shared with him that he keeps yawning during classes and the homework from all these "cultivate excellence" institutions has exhausted him. How then can he still listen to his teacher? When the students sit in class, what they see is only an illusion. Such a concept has made a fifth grader grow a little white hair, expecting more to grow with age. The conclusion that the doctor made was that the boy is facing too much mental pressure; instead, he should be carefree, happily growing up. This news may be "extreme," but it reveals the academic pressure that shadow education places on 
students, leaving them "breathless." The ballgame of "reducing the burden in schools but increasing the burden outside schools" changes a happy childhood to an unhappy one, making what is free, unfree; this is not conducive to the development of students' natural attributes.

\section{Conclusion}

There is a need to focus more on shadow education for primary school students. The negative implications of shadow education are accumulated over time. Therefore, they cannot be contained immediately. It requires the joint efforts and close coordination of shadow institutions, the government, families, schools, and the society. In the course of development, the principal aspect of the principal contradiction plays a decisive role. Therefore, for the governance of the negative implications of shadow education, it plays a decisive role in the main aspect of its own development; that is, the internal factors. Only when shadow education truly operates according to the law of physical and mental development of primary school students, develops "people-oriented" characteristics, and achieves high school quality as well as satisfactory educational results, then, there will be an improvement in its social recognition, and the motherland will be more "elegant in full bloom," which is the foundation of shadow education.

\section{Funding}

This study was supported by the School-Level Teaching and Research Project of Jilin Engineering and Technology Teacher's College - Research on the Precise Poverty Alleviation Path of Secondary Vocational Education to Rural Areas - Taking Changchun City of Jilin Province As An Example; Jilin Province Vocational Education and Adult Education Teaching Reform Research Project (2021ZCY338) - Research on the Application of Blended Teaching Mode for Preschool Education Majors in Higher Vocational Schools - Take "Kindergarten Games" As An Example; Jilin Engineering Normal University School-Level Scientific Research Projects (Public List XII) - Chinese and Foreign Preschool Education History Course Thinking and Practice.

\section{Disclosure statement}

The author declares that there is no conflict of interest.

\section{References}

[1] Lin G, 2014, Education Is Useless - Back to the Essence of Education, Peking University Press, Beijing, 48.

[2] Kast V, 2003, Rage and Attack, SDX Joint Publishing Company, 84.

[3] Tan X, 2010, Research on the Negative Functions of Education and Its Prevention Strategies, Nanchang University, Jiangxi. 